\title{
CONTRIBUIÇÕES DE UMA EXPERIÊNCIA PEDAGÓGICA EM EDUCAÇÃo AMBIENTAL
}

\author{
Maria Socorro Duarte da Silva Couto ${ }^{1}$ \\ Cláudia Sampaio Guimarães ${ }^{2}$ \\ Marlei de Fátima Pereira ${ }^{3}$
}

\section{Resumo}

Evidencia-se, com este estudo, as contribuições de uma experiência pedagógica em Educação Ambiental (EA) em uma escola municipal de Jataí-GO, em 2013 e 2014. Buscou-se, assim, verificar os elementos necessários à prática pedagógica em EA, contemplando a articulação e elaboração de propostas entre professores de áreas distintas do conhecimento. Para tal, considerou-se os aspectos da construção, discussão e avaliação de três propostas pedagógicas. Tais propostas partiram do tema sustentabilidade e foram desenvolvidas por meio de uma pesquisa interventiva focada na discussão em grupo, que geraram alguns resultados tais como: articulação entre as disciplinas do planejamento à execução das ações; inserção da EA no contexto escolar a partir da reconstrução do Projeto Político Pedagógico da escola e o estabelecimento de estratégias a partir de situações-problema. A proposta destaca que, por meio de projetos, é possível trilhar um caminho rumo à construção coletiva em EA enquanto prática pedagógica educacional interdisciplinar.

Palavras-chave: Educação ambiental. Articulação-áreas-ensino. Prática pedagógica.

\section{CONTRIBUTIONS OF AN EDUCATIONAL EXPERIENCE IN ENVIRONMENTAL EDUCATION}

\begin{abstract}
This study seeks to highlight the contributions of an educational experience in Environmental Education (EE) in a municipal school of Jataí-GO, in 2013 and 2014. The study also aims to verify the elements necessary for the pedagogical practice in EE, considering the articulation and the elaboration of proposals among teachers of different areas of knowledge. Therefore, aspects of construction, discussion and evaluation of three educational proposals were considered. Such proposals have emerged from sustainability issue and were developed through an interventional research focused on group discussion, which obtained some results such as: engagement among the disciplines from planning to implementation of actions; introduction of $\mathrm{EE}$ in the school context beginning with the reconstruction of the school Pedagogical Political Project; and the establishment of strategies from problem situations. The proposal emphasizes that, through projects, it is possible to walk a path towards collective construction in $\mathrm{EE}$ as an interdisciplinary educational pedagogical practice.
\end{abstract}

Keywords: Environmental education. Joint-areas-education. Pedagogical practice.

\footnotetext{
${ }^{1}$ Professora titular do Programa de Pós-Graduação em Educação para Ciências e Matemática e do Programa de Pós-Graduação em Tecnologia de Processos Sustentáveis do Instituto Federal de Educação, Ciências e Tecnologia de Goiás (IFG).

${ }^{2}$ Mestre em Educação e Professora efetiva da Escola Municipal Professor João Justino de Oliveira da cidade de Jataí - GO

${ }^{3}$ Professora efetiva do Instituto Federal de Educação, Ciências e Tecnologia de Goiás (IFG) - Câmpus Aparecida de Goiânia, Professora titular do Programa de Pós-Graduação em Educação para Ciências e Matemática do IFG.
} 


\section{CONTRIBUCIONES DE UNA EXPERIENCIA PEDAGÓGICA EN EDUCACIÓN AMBIENTAL}

\section{Resumen}

Se discute en este estudio las contribuciones de una experiencia pedagógica en Educación Ambiental (EA) en una escuela de la municipalidad de Jataí- GO, realizada en 2013 y 2014. Se trató de verificar los elementos necesarios para la práctica pedagógica en EA, teniendo en cuenta la articulación y elaboración de propuestas entre profesores de diferentes áreas del conocimiento. Para eso, se consideró los aspectos de la construcción, discusión y evaluación de tres propuestas pedagógicas. Esas propuestas surgieron de la temática sostenibilidad y fueron desarrolladas por medio de una investigación de intervención enfocada en la discusión en grupo. Ese debate generó algunos resultados tales como: la articulación entre las asignaturas de la planificación cuya finalidad es la ejecución de las acciones; inserción de la EA en el contexto escolar a partir de la reconstrucción del Proyecto Político Pedagógico de la escuela; y o establecimiento de estrategias a partir de una situación problema. La propuesta destaca que, por medio de proyectos, es posible seguir un camino rumbo a la construcción colectiva en la EA como una práctica pedagógica educacional interdisciplinaria.

Palabras clave: Educación ambiental. Articulación áreas enseñanza. Práctica pedagógica.

\section{Introdução}

Um dos grandes desafios da sociedade de produção capitalista está na conciliação entre o crescimento urbano e a qualidade ambiental da vida em sociedade. Nesse contexto, a práxis escolar é desafiada a trabalhar os temas ambientais em suas várias dimensões: social, econômica, política, cultural e ecológica. Compreender a importância da dialogicidade entre aspectos sociais e ecológicos no universo escolar é algo que irá abranger diferentes áreas de ensino. Além disso, proporciona debates acerca de valores e premissas que norteiam as práticas sociais, e, assim, propõe espaço para sugerir mudanças na forma de se pensar e transformar o conhecimento e as práticas educativas (JACOBI, 2005).

A educação ambiental (EA) implica em um trânsito entre diferentes disciplinas. Isso porque, além de considerar a realidade ecológica e social do público local, abrange práticas pedagógicas que visam um processo formativo também da percepção e da necessidade de mudanças atitudinais frente às problemáticas ambientais na vida em sociedade. Nesse contexto, os professores desempenham um papel "estratégico e decisivo na inserção da educação ambiental no cotidiano escolar, qualificando os alunos para um posicionamento crítico" (JACOBI, 2005, p. 233).

Evidenciou-se, assim, o objetivo da pesquisa, que consistiu em verificar os elementos que seriam necessários à prática pedagógica em EA que contemplasse a articulação entre professores de diferentes áreas de conhecimento na formulação/adesão/discussão/avaliação de propostas para os problemas ambientais identificados na realidade do entorno da escola. Haja vista a unidade encontrar-se inserida em região de mananciais, a pesquisa proporcionou $o$ desenvolvimento de atividades relativas a questões ambientais, tais como: a Conferência sobre Meio Ambiente, a Feira de Ciências e Projetos Ambientais. Para isso, adotou-se a pesquisa participativa, que favoreceu a integração entre o pensar e o agir de forma coletiva (FRANCO, 2005). A metodologia tornou possível a reflexão-ação dos sujeitos imbuídos no processo. 


\section{Dimensões da Educação Ambiental}

Quando se fala em educação ambiental, é preciso considerar a variedade de dimensões que ela abrange, seja ecológica, política, cultural, econômica e social. Tal complexidade pode ser encontrada tanto em discursos quanto em documentos produzidos nessa área. Há uma dialética entre essas dimensões e a rede de relações estabelecidas entre elas que é preciso considerar no contexto educacional, principalmente no que se refere às diferentes correntes teóricas que fundamentam a práxis da EA. Algumas dessas correntes se destacam pelo caráter problematizador e dialógico, por exemplo, a crítico-reflexiva que "[...] traz uma abordagem crítica, emancipatória e práxica, marcada pelo pensamento de Paulo Freire e pelos princípios da Teoria Crítica" (MORALES, 2009, p. 49).

Nesse contexto, os processos formativos em EA devem considerar, também, os valores culturais e políticos das comunidades, pois eles contêm informações explicativas sobre as demais relações existentes que envolvem os aspectos econômicos, sociais e ecológicos da população (SATO; PASSOS, 2011). Destaca-se, ainda, que a organização social é fruto de um processo histórico de dominação da natureza, de uma supervalorização das relações de poder em detrimento de valores primordiais à sustentabilidade ambiental, evidenciadas pelas transformações ocasionadas pelo avanço tecnológico e científico na forma de vida e na cultura das sociedades.

A possibilidade de um casamento entre sistema capitalista e desenvolvimento sustentável, ou uma real sustentabilidade em um contexto de crise socioambiental, evidenciam a necessidade de se propor uma EA que chame a atenção para os ecossistemas e os recursos naturais frente ao discurso criado por grandes nações que vendem uma ideia de como praticar o desenvolvimento sustentável. Há um fator comum entre a contradição de um desenvolvimento que se deseja e o que realmente ocorre e a sustentabilidade real que não existe no capitalismo? São questões que perpassam o desafio de toda e qualquer proposta de EA em um ambiente educativo. Nesse contexto, a compreensão do conceito de sustentabilidade, partindo de valores sociais, culturais e políticos é imprescindível no campo educacional. Tem-se presente que é a partir de uma formação ambiental crítica que será possível reconstruir uma sociedade mais consciente de seu papel.

Leff (2012), outro teórico da área, aponta que a transição para a sustentabilidade provoca a necessidade de transcender as contradições entre racionalidade econômica e racionalidade ambiental. Assim, é imprescindível que haja debates no ambiente educacional, cuja pauta elenque as contradições do desenvolvimento sustentável no contexto capitalista. Para o autor, quanto maior a percepção das inter-relações entre as dimensões constituintes da estrutura social, melhor a compreensão dos fenômenos socioambientais e mais profícuas as formas de participação popular.

\section{Interdisciplinaridade e a Educação Ambiental}

Fator primordial na EA, a interdisciplinaridade descarta toda e qualquer compartimentalização do conhecimento. Se se parte da legislação e documentos da área, todos apontam para a natureza transversal e interdisciplinar da EA. No entanto, estudiosos ressaltam as dificuldades encontradas, inclusive em cursos de formação de educadores, para viabilizar essa prática. É notória a complexidade do desenvolvimento dos saberes ambientais nos sistemas educativos. O trabalho interdisciplinar é tido como possível solução frente ao quadro de desarticulação do conhecimento, fruto da estrutura curricular vigente, na qual os conteúdos dos diversos componentes curriculares não se integram e os elementos culturais formadores do saber são considerados de fontes isoladas entre si (SEVERINO, 1998). Porém, o planejamento e a aplicação da interdisciplinaridade têm se mostrado um enorme desafio, cuja 
maior dificuldade consiste em adaptar-se ao contexto vivido, respeitando a realidade dos envolvidos no processo.

Nesse contexto, alguns estudos apontam elementos importantes relativos aos desafios e obstáculos na prática pedagógica interdisciplinar, ora citados: possibilita a interdependência, o compartilhamento, o encontro, o diálogo e transformações sociais (TRINDADE, 2008); possibilita o pensar em uma escola que respeite e perceba o aluno com potencialidades e capacidade de expressar-se (JOSÉ, 2008); facilita a interação e o diálogo; auxilia na definição de um projeto que prioriza a totalidade do conhecimento (ALVES, 2013); proporciona a integração teoria/prática (TOZONI-REIS, 2004); favorece a ligação entre interdisciplinaridade e didática (LENOIR, 1998); estabelece o diálogo entre o conhecimento do senso comum e conhecimento científico (FAZENDA, 2010), dentre outros. Tais elementos, segundo os autores supracitados, estão entre os aspectos essenciais que representam a possibilidade de superação dos obstáculos ao desenvolvimento da interdisciplinaridade na educação.

\section{Metodologia e planejamento das propostas pedagógicas}

O caminho metodológico percorrido neste trabalho considerou a elaboração e aplicação de três propostas pedagógicas realizadas na Escola Municipal Professor João Justino de Oliveira, na cidade de Jataí-GO, situada próximo a duas áreas verdes, a Mata do Açude e a Mata do Queixada; uma conferência sobre meio ambiente; uma feira de ciências e o desenvolvimento de projetos ambientais. A localização geográfica da escola possibilitou a interação com o meio ambiente, além de ser uma região cortada por cursos d'água, o que favoreceu o estabelecimento dos primeiros moradores da região. Ou seja, a presença de áreas verdes destaca a relevância de o patrimônio cultural e histórico nas cercanias da unidade escolar ser incluso na proposta de Educação Ambiental. Torna-se importante contextualizar o espaço evidenciado para que se tenha presente a importância da EA na vida da escola e do município. São duas matas em evidência: a Mata do Açude, que se constitui em uma área de proteção ambiental e faz parte do patrimônio histórico da cidade, e a Mata do Queixada, que é uma reserva privada. Às margens das matas, de um lado, há diversos loteamentos, que a cada dia avançam rumo à mata, o que promove uma perda substancial de sua extensão. Do outro lado, a zona rural com lavouras e desmatamentos crescentes que também ameaçam esse ecossistema. Carvalho e Scopel (2010, p. 13) apontam que, em algumas características da vegetação encontradas no local "[...] não há homogeneidade na fitofisionomia da Mata, sendo encontradas diversas nuances do Cerrado, como mata ciliar e de galeria [...]". Eles explicam que a expansão da cidade em direção ao divisor de águas do Córrego Jataí e do Queixada comprometem a preservação da Mata do Queixada e interferem no ciclo, qualidade e quantidade de água da bacia. Os problemas ambientais estão bem visíveis, pois há lixo em locais inapropriados; desmatamento para implantação de novos loteamentos; pressão sobre as espécies vegetais e animais, dentre outros.

Esse cenário tornou-se o campo de estudo e análise da equipe de professores. A constatação foi imediata, impondo-se a proposição de um trabalho articulado em educação ambiental interdisciplinar, cujo laboratório seriam as áreas verdes que cercam a unidade escolar. $\mathrm{O}$ foco e os rumos da pesquisa também ficaram claros ao exigir um eixo norteador (a sustentabilidade); um possível caminho, favorecer um espaço de discussão, planejamento, aplicação de propostas metodológicas e a inserção dos temas ambientais no Projeto Político Pedagógico (PPP) da escola. Cientes do seu papel, os professores das áreas de Geografia, Português, Matemática, Ciências, História, Educação Física e Inglês perceberam que poderiam contribuir e aprender com a proposta.

O que e como fazer? Primeiramente, a equipe interdisciplinar buscou compreender que 
tipo de desenvolvimento seria capaz de conciliar crescimento urbano e qualidade ambiental em uma sociedade capitalista. A partir daí, percebeu-se que, assim como em outros setores, também caberia à educação assumir uma prática escolar que envolvesse os temas ambientais, em suas várias dimensões (social, econômica, política, cultural e ecológica).

Tal proposta ultrapassa a sala de aula e conteúdo específico de cada área. Necessita ser planejada em conjunto com uma proposta da gestão escolar como um todo, como lembra Jacobi (2005, p. 242-243), a reflexão ambiental dinamiza o espaço educativo "[...] para compreender a gestação de novos atores sociais que se mobilizam [...], para um processo educativo articulado e compromissado com a sustentabilidade e a participação, [...] privilegia o diálogo e a interdependência de diferentes áreas de saber".

Nesse contexto, percebeu-se que a prática educativa abrange, também, a transformação de hábitos. Pensar a sustentabilidade exige formação em cidadania ambiental. Isso fortalece a reflexão e o desenvolvimento de ações que proporcionam o cultivo e o cuidado de um ambiente mais saudável e mais equilibrado. Dessa forma, as propostas pedagógicas foram planejadas e avaliadas por meio de discussões em grupo, realizadas, quinzenalmente, na própria escola. Sobre as potencialidades dessa estratégia, Flick (2009) afirma que a discussão em grupo tem como característica a produção de opiniões, trocadas cotidianamente, que possibilitam ao grupo corrigir e/ou alterar opiniões não socialmente compartilhadas pelos demais integrantes e que comprometem a eficácia da proposta. Assim, o grupo constitui-se em uma ferramenta para a reconstrução de ideias individuais mais apropriadas ao coletivo.

Ao longo do desenvolvimento das propostas, após cada discussão grupal, confeccionava-se um relatório destacando as participações, ideias debatidas e decisões tomadas. Isso possibilitou uma análise objetiva das possibilidades e dificuldades docentes na realização das propostas pedagógicas adotadas na educação ambiental, a partir do tema sustentabilidade, articulada entre as diferentes disciplinas. Importante lembrar que a pesquisa ocorreu entre os anos de 2013 e 2014; o público alvo foram professores e alunos do $6^{\circ}$ ao $9^{\circ}$ ano da Escola Municipal Professor João Justino de Oliveira na cidade de Jataí-GO.

A hipótese considerou que a educação ambiental nem sempre é compreendida como tema transversal inerente a todas as áreas do conhecimento. Partiu da constatação de que a maioria dos professores dispensa pouco tempo à EA em suas aulas. A título de observação, Guimarães (2012) esclarece que a visão fragmentária potencializa a tendência, nas escolas, do desenvolvimento de ações isoladas, voltadas para o comportamento individual do aluno, descontextualizada da realidade socioambiental e desvinculada do Plano Político Pedagógico (PPP), apesar do caráter transversal proposto nos Parâmetros Curriculares Nacionais (PCN). Destarte, o trabalho tratou-se de uma pesquisa interventiva: buscou descrever uma realidade específica a respeito de como docentes de diferentes áreas se articulam diante do desafio de uma proposta em educação ambiental, planejada coletivamente. E, considerando os procedimentos técnicos de coleta e análise de dados, a pesquisa enquadra-se em um estudo de campo com algumas características da pesquisa-ação.

Observa-se o pressuposto de que a pesquisa e a ação devem caminhar juntas em prol da transformação na prática pedagógica. A necessidade de valorização dos temas ambientais como área de estudo e como responsabilidade coletiva pautou-se em uma pesquisa interventiva com viés fundamentado nos conhecimentos gerados pela pesquisa-ação, assim definida por Severino (2007, p. 120): "A pesquisa ação é aquela que, além de compreender, visa intervir na situação, com vistas a modificá-la".

Segundo Dionne (2007, p. 35), "a pesquisa-ação permite que adquiram conhecimentos novos e, por isso, é considerada uma metodologia de pesquisa". A pesquisa em questão percorreu dois caminhos: pesquisa no campo e plano de ação. Ou seja, pesquisa e ação podem caminhar juntas, em mão dupla: pesquisa com ação/ação com pesquisa. A autora esclarece 
que a pesquisa-ação crítica origina a reflexão sobre a ação, coletivamente.

Ressalta-se que o planejamento da ação se iniciou com a aplicação de um questionário aos professores e pela análise do PPP da escola, no intuito de verificar como os temas ambientais encontravam-se inseridos no documento. Quanto ao questionário, possibilitou verificar dados gerais sobre a formação docente, o tempo de experiência, a carga horária e, principalmente: concepção sobre interdisciplinaridade; conceito de educação ambiental; como a EA era trabalhada na escola. Além disso, o docente teve a possibilidade de sugerir práticas pedagógicas na área de educação ambiental, tanto em sala de aula como no PPP da escola. Assim, a partir daí foi possível realizar o diagnóstico do perfil dos professores, a análise do PPP e o planejamento/aplicação das três propostas pedagógicas: conferência sobre meio ambiente, feira de ciências e o desenvolvimento de projetos ambientais. Em média, quinze professores de diferentes áreas participaram dessa etapa.

\subsection{Coleta de dados}

Para a coleta de dados, foram priorizadas as seguintes técnicas: filmagem, registro fotográfico, observação participante, questionário e entrevista. Sobre esses instrumentos de coleta, Gil (2007, p. 53) explica que a pesquisa desenvolvida pela observação direta das atividades do grupo ajuda a captar explicações e interpretações. Além disso, "[...] esses procedimentos são geralmente conjugados com muitos outros, tais como análise de documentos, filmagem e fotografias". Na produção de vídeos, foram escolhidas as técnicas de filmagem e registro fotográfico, que contaram com a participação de alunos, professores e componentes do grupo de discussão. Um destaque para a interação entre professores na aplicação das propostas e entrevistas.

Em se tratando da observação participante, realizou-se o registro escrito dos relatos ocorridos no decorrer de troca de informações com professores, orientações aos alunos, análise dos vídeos e por ocasião da retomada do planejamento, esclarecimento de dúvidas e prestação de apoio aos processos em desenvolvimento. Quanto ao plano de ação, considerouse o tempo de participação dos professores no horário destinado ao encontro pedagógico, com duração de cinquenta minutos cada. No total, ocorreram treze encontros, cujos temas de discussão abarcaram questões tais como: planejamento e avaliação das propostas pedagógicas; estudos sobre sustentabilidade; configuração da educação ambiental e sua institucionalização na educação formal; elementos para elaboração de um projeto ambiental; apresentação de projetos elaborados e desenvolvidos pelos docentes.

A intervenção proposta fundamentou-se em projetos educacionais, com a participação efetiva de alunos e docentes. Nesse sentido, Moura e Barbosa (2007, p. 23) afirmam que são projetos com objetivos definidos "[...] com a finalidade de planejar, coordenar e executar ações voltadas para melhoria de processos educativos e de formação humana, em seus diferentes níveis e contextos". Por fim, as discussões em grupo e as entrevistas possibilitaram a aquisição de dados sobre: a concepção dos professores acerca do desenvolvimento de projetos interdisciplinares articulados; partilha de experiências em trabalhos interdisciplinares; verificar a relevância atribuída ao processo pedagógico articulado; e, detectar as dificuldades e possibilidades de realização da EA na unidade escolar. Quanto aos questionários aplicados aos professores, possibilitaram a verificação da eficácia dos trabalhos desenvolvidos.

\subsection{Aplicação das propostas didáticas}

A aplicação das propostas didático-pedagógicas ocorreu em três momentos específicos: conferência sobre meio ambiente, feira de ciências e o desenvolvimento de 
projetos ambientais. Na primeira proposta, da conferência ambiental, o ponto de partida para detectar os principais problemas ambientais percebidos pelos alunos a partir contexto geográfico concreto. Que ferramentas ajudariam a atingir o objetivo do evento? Após o planejamento, delineou-se o plano de ação, ora descrito: apresentação de um projeto sobre a Mata do Queixada (grupo de alunas); apresentações de slides intercaladas com músicas sobre o meio ambiente; palestra sobre sustentabilidade (professor da Universidade Federal de Goiás); interpretação da música "Planeta Água", de Guilherme Arantes, em Libras; declamação de poesias sobre a temática; fala das autoridades convidadas (representante da Secretaria Municipal do Meio Ambiente, da Secretaria Municipal de Educação e da direção da escola); encerramento do evento. Após a realização do evento, aplicou-se um questionário avaliativo no intuito de coletar informações sobre a pertinência do tema às necessidades da escola; aspectos positivos e que poderiam ser melhores trabalhados; participação dos alunos; outros pontos relevantes e sugestões.

No que se refere ao desenvolvimento da segunda proposta, feira de ciências, considerou-se o fato de a escola localizar-se, geograficamente, entre as áreas verdes da Mata do Queixada e da Mata do Açude; nessa última, há um Centro de Pesquisa (inativo), sendo que no local funciona a Secretaria do Meio Ambiente do município. Segundo Bizzo (2009, p. 98), a feira de ciências é uma proposta importante para o desenvolvimento crítico do sujeito, da cidadania e da integração social, pois pode "[...] estimular uma postura investigativa nos alunos dissociada de uma visão ingênua do que seja a imagem da ciência e o trabalho do cientista". Nesse sentido, os projetos da feira estavam relacionados a estudos sobre os problemas ambientais identificados nas matas do Queixada e do Açude.

As ferramentas utilizadas na feira de ciências consistiram em registros fotográficos; conversas informais com moradores próximos às áreas verdes; referências e registros existentes sobre as matas. Dentre os temas abordados nos projetos, um destaque para a água, queimada, desmatamento, poluição, importância do Cerrado, economia de água e luz, reciclagem e preservação ambiental, lixo, conservação de matas ciliares, equilíbrio dos ecossistemas. Para avaliar a proposta pedagógica da feira de ciências, realizou-se uma entrevista com seis professores de $6^{\circ}$ ao $9^{\circ}$ ano, no intuito de verificar a articulação entre as diferentes disciplinas; apreender ideias quanto ao planejamento e ao desenvolvimento da proposta; compreender as dificuldades e as possibilidades da inserção da EA na visão dos docentes.

Quanto ao desenvolvimento e aplicação de projetos ambientais na escola, a terceira proposta, apresentou-se aos docentes possíveis temáticas sobre a natureza interdisciplinar e transversal da educação ambiental, institucionalização da EA e conceito de desenvolvimento sustentável. Em seguida, os docentes elaboraram e apresentaram os projetos aos demais membros do grupo. Temas sugeridos e trabalhados pelos docentes: lixo eletrônico; entulho nas margens das matas; inclusão através da horta escolar; a limpeza na escola. As informações pertinentes a uma educação ambiental crítica pautaram-se nos estudos de Loureiro (2007), que destaca os desafios para o fazer pedagógico, tais como: repensar objetivos de projetos e práticas pedagógicas; considerar as características sociais, econômicas e culturais do grupo; agir em consonância para a sustentabilidade local; a consciência crítica das relações que determinam as práticas culturais. Buscou-se, assim, refletir sobre uma educação que compreenda as relações sociais, ecológica, econômica, política e cultural na sociedade como um todo. Os docentes sugeriram as ações seguintes a essa etapa: debate com pais e alunos sobre EA; criação de metas na EA; encaminhamento dos problemas abordados aos políticos locais responsáveis no sentido de busca de soluções; e, por fim, acionar as mídias locais para divulgação dos trabalhos realizados. 


\subsection{Análise dos dados}

Após execução das propostas estabelecidas (conferência sobre meio ambiente, feira de ciências e projetos ambientais), fez-se, com os professores, uma avaliação geral dos projetos por meio do preenchimento de um questionário e depoimento gravado pelos nove docentes presentes no último encontro. A etapa de análise e a interpretação dos dados ocorreram conforme o proposto por Bardin (2011), baseando-se no questionário inicial, na análise do PPP da escola, nos relatórios das discussões em grupo, nas observações, nos registros fotográficos realizados, nas filmagens e na entrevista de avaliação da proposta de intervenção pedagógica. A categorização, feita por meio de temas, fundamentou-se na reflexão sobre o objeto de pesquisa, que subsidiou a seleção dos dados submetidos para análise e as informações relevantes sobre as contribuições das três propostas realizadas na escola. Os dados possibilitaram uma análise qualitativa, observando a natureza, a extensão da amostra, os instrumentos de pesquisa e os pressupostos teóricos que nortearam a investigação (GIL, 2007).

Quanto à organização, a análise ocorreu em três fases, conforme sugere Bardin (2011, p. 125): pré-análise; a exploração do material; e tratamento dos resultados, a inferência e a interpretação. A pré-análise tem por objetivo "tornar operacionais e sistematizar as ideias iniciais, [...] num plano de análise". Ou seja, organiza-se e seleciona-se o material submetido à análise (o corpus). Os indicadores, constituídos por palavras-chave, revelaram-se essenciais à formulação das categorias de análise, relacionados às dimensões, dificuldades, possibilidades, educação ambiental e proposta pedagógica. $\mathrm{Na}$ etapa de exploração do material, as mensagens foram agrupadas em quatro categorias de análise: dimensões da educação ambiental nas propostas pedagógicas; articulação entre as áreas do conhecimento; percepção docente sobre interdisciplinaridade; e, inserção da educação ambiental na escola. Na última etapa, organização da análise, o tratamento dos resultados e a interpretação para, então, inferir, interpretar e atribuir significação às informações obtidas nos dados coletados.

\section{Resultados e discussões dos dados}

Organizados em cinco tópicos (os quatro primeiros referentes às categorias analisadas e, o último, às reflexões sobre o processo de construção, aplicação e avaliação das propostas em EA realizadas na escola), chegou-se aos resultados ora explicitados.

\subsection{Dimensões da Educação Ambiental}

$\mathrm{Na}$ categoria sobre as dimensões da educação ambiental, procurou-se identificar as dimensões política, social e ecológica nas propostas pedagógicas desenvolvidas. A dimensão política apareceu, sutilmente, nas atividades programadas por meio de sugestões de propostas metodológicas (presentes em todas as propostas); de participações em mobilização de campanhas sobre meio ambiente fora da escola (projeto ambiental elaborado por docente); de temas que discutem características políticas das relações humanas com o meio; de debates sobre os problemas ambientais locais; reflexão crítica sobre a EA promovida por empresas privadas (conferência ambiental). No entanto, notou-se a ausência de articulação no sentido de incentivar a tomada de decisões que implicassem em uma participação mais crítica dos estudantes junto a órgãos públicos locais.

Observou-se, ainda: predominância da dimensão ecológica da EA nos posicionamentos dos participantes, na indicação dos temas ar, solo, água e vegetação (conferência ambiental), nos aspectos ecológicos presentes na reflexão dos problemas ambientais decorrentes do lixo (produção, destino e riscos); ações de higiene e limpeza na 
escola (feira de ciências e projetos ambientais). Constatou-se a dimensão social na indicação de temas pelos professores e reflexões voltadas para o contexto do aluno: aspectos sociais e culturais, lixo, reciclagem, economia de água e luz, e na palestra sobre sustentabilidade (relação entre sociedade e meio ambiente). Porém, percebeu-se que os professores pouco se alertaram para o caráter político e econômico em seus projetos, embora essas dimensões tenham sido abordadas nas discussões em grupo.

Destaca-se que as ações realizadas não foram suficientes para imprimir uma ideia diferenciada dos valores políticos implícitos na prática docente. Entretanto, revelaram-se potencialmente geradoras de uma nova percepção para a atuação enquanto educador ambiental. Permanece o desafio de um processo formativo continuado para uma prática orientada, que inclua valores culturais, econômicos e políticos envolvidos na relação ser humano-natureza-sociedade.

\subsection{Articulação entre as Áreas do Conhecimento}

No que se refere à articulação entre as diferentes áreas do conhecimento, alguns aspectos mereceram destaque: solidariedade, cooperação, interação, troca de experiências entre os docentes; discussões que contribuíram no processo comunicativo, definição de estratégias para a superação de dúvidas e dificuldades. Não houve abordagem específica em cada área do conhecimento, porém os projetos definidos e constituídos no grupo foram executados por meio da participação de todos os envolvidos. De acordo com Tozoni-Reis (2004), a integração das atividades de ensino interfere na qualidade de ensino, inclusive na formação dos educadores ambientais. Porém, se a organização do currículo estiver fragmentada e desarticulada inviabiliza uma formação humana consistente dos educandos, em particular, dos futuros educadores ambientais. Talvez, isso explique o porquê das dificuldades encontradas pelos professores em identificar as formas de articulação entre as áreas e confirme o quanto é complexo realizar um trabalho interdisciplinar na prática. Com relação à EA interdisciplinar, na fase inicial da pesquisa, um dos professores afirmou que isso não acontecia: "não é só na nossa escola que não acontece à educação ambiental de forma articulada entre as áreas de ensino, é um problema encontrado provavelmente em muitas outras" (ENTREVISTA PEB $\left.{ }^{4}, 2013\right)$.

Muitos professores demonstraram dificuldades em estabelecer formas de articulações entre as áreas; no entanto, revelaram conhecimentos essenciais a uma prática interdisciplinar, tais como: interação docente, auxílio mútuo, mobilização de conhecimentos das diferentes áreas para elaboração e execução de projetos. Também perceberam, após a realização das propostas na escola, mudanças em sua visão sobre a educação ambiental. No geral, há uma carência muito grande nos cursos de formação de professores para o trabalho interdisciplinar. Dessa forma, pela natureza transversal e interdisciplinar própria da educação ambiental, e por todos os demais fatores citados, torna-se uma tarefa árdua a inserção da EA no espaço escolar. Verifica-se que a mudança deve partir das licenciaturas, no sentido de superar a fragmentação do conhecimento, possibilitando a transversalidade das temáticas ambientais.

A título de ilustração, na fase inicial de planejamento da feira de ciências, os professores demonstraram muita insegurança em trabalhar com temas que geralmente não são explorados na disciplina. Afirmações como "[...] essas temáticas são novas para mim. Como não sou da área é difícil trabalhar com elas, pela falta de conhecimento" (ENTREVISTA $\left.\mathrm{PEB}^{5}, 2013\right)$, registram a impressão docente que a educação ambiental é um conhecimento pertinente à área de Ciências. Por isso, tornou-se necessário vários momentos de estudo para que o grupo de educadores clarificassem impressões e conceitos, no intuito de compreender

\footnotetext{
${ }^{4}$ Realizada no início da pesquisa.

${ }^{5}$ Realizada durante o planejamento da Feira de Ciências.
} 
melhor o caráter transdisciplinar e interdisciplinar da educação ambiental.

Ao final da aplicação da proposta da feira de ciências, percebeu-se o seu valor em propiciar a articulação entre as áreas do conhecimento, conforme expresso pelos professores no momento da avaliação:

Sou leigo no assunto, sobre educação ambiental, mas é um começo nosso, tanto para os alunos como pra nós que orientamos, eu acho que sempre tem muita dificuldade, sempre tem alguns contratempos, gente que trabalhou mais, gente que trabalhou menos, mas eu acho que o caminho que nós estamos seguindo está certo (ENTREVISTA PEB $\left.{ }^{6}, 2014\right)$.

No geral, a articulação entre as áreas do conhecimento ocorreu por meio do envolvimento da comunidade escolar (direção, coordenação pedagógica, porteiro, equipe da limpeza, auxiliar de biblioteca, Secretaria Municipal de Educação, alunos e professores); pela interação docente (voz dos atores no processo) na etapa de planejamento; pelo auxílio mútuo; pela mobilização de conhecimentos das diferentes áreas para elaboração e execução de projetos; pela construção coletiva de saberes e pela troca de experiência (dialogicidade). Percebe-se que houve mudanças na visão sobre a educação ambiental.

\subsection{Percepção docente de interdisciplinaridade}

Quanto à percepção docente de interdisciplinaridade, a dificuldade é colocá-la em prática em decorrência de fatores tais como: falta de formação para o trabalho interdisciplinar; não disponibilidade de horário para o diálogo com outras áreas sobre os conteúdos; indisposição para o planejamento conjunto; e, a carga exaustiva de trabalho. Porém, apesar dos obstáculos encontrados, os professores percebem os seguintes benefícios da interdisciplinaridade: aprofundamento da temática; visão ampla do conteúdo sob o olhar de outras áreas; aprendizagem compartilhada; maior facilidade em atingir os objetivos propostos; construção do conhecimento em cooperação com todos os envolvidos. Verifica-se, portanto, que os docentes confirmam a relevância do trabalho interdisciplinar, porém, evidenciam diversos aspectos que prejudicam ou impossibilitam tal interação. Interessante observar que parte dos docentes define a interdisciplinaridade como significativa; contudo, precisa sair do plano da ideologia e se tornar fato consumado. Segundo Fazenda (2010, p. 171), quando a interdisciplinaridade é apenas pronunciada " [...] os educadores, em especial, não sabem bem o que fazer com ela. Sentem-se perplexos frente à possibilidade de sua implementação na educação. [...] percebe-se, em todos esses projetos, a marca da insegurança".

Ressalta-se que os docentes perceberam o valor do trabalho em equipe, da interação e da cooperação para a condução de propostas interdisciplinares. Um grupo unido propõe ideias que são incorporadas a outras já existentes, proporcionando a construção de estratégias de ensino cada vez mais elaboradas. Os professores foram unânimes em afirmar a importância da interdisciplinaridade e a sua concretização no ensino-aprendizagem. Alguns pontos expostos por eles justificam essa prática, por exemplo: interação entre professor-professor, professoraluno; participação conjunta (integração) que favorece resultado positivo e a percepção por parte dos alunos de que os conteúdos estão interligados nas diferentes disciplinas, proporcionando uma visão mais ampla sobre os temas abordados. Essa compreensão encontra-se expressa na fala dos professores: "Creio que nós estamos vivendo um momento no qual falamos em interdisciplinaridade. Teve esse envolvimento, [...] mas estou observando a deficiência na formação dos próprios professores. Talvez uns não procurem [...] fazer uma formação continuada"; "Então eu percebi que nós estávamos em harmonia. Eu percebo que

\footnotetext{
${ }^{6}$ Realizada durante o processo de avaliação da Feira de Ciências, 2014.
} 
nossa escola melhorou bastante, nós estamos mais unidos pra resolver as coisas. Nós estamos tentando falar à mesma língua. Se os professores continuarem assim, nós teremos bons frutos pra colher" (ENTREVISTAS PEB's, 2014) ${ }^{7}$.

De acordo Trindade (2008), é necessário pensar sobre as atitudes tidas como interdisciplinares: a humildade perante os limites do próprio saber; a paciência para analisar o que está estabelecido (para que as dúvidas surjam e o novo germine); ater-se a possibilidades de superação de desafios; respeito ao velho para visualizar o novo: cooperação; trocas de experiências e desejo de aprender com o outro. Tudo isso propicia transformações.

\subsection{Inserção da Educação Ambiental na Escola}

Sobre a inserção da educação ambiental na escola, buscou-se identificar as principais dificuldades e possibilidades desse processo, a saber: necessidade de rever o PPP da escola, enquanto documento que contempla metas e ações, e inserir a educação ambiental. Além disso, é um instrumento que prevê o planejamento das ações, a continuidade e/ou complementação/elaboração de novos projetos. No geral, constatou-se o empenho conjunto da equipe imbuída na qualidade das apresentações, que trouxeram à tona o debate com foco na sustentabilidade, pautado nos problemas ambientais locais. O sucesso da ação resultou em um planejamento coletivo do projeto desenvolvido. Ao final, apresentou-se o resultado do trabalho em EA realizado pelos professores e alunos, que puderam expressar-se, em conferência, sobre a degradação e as atitudes das pessoas em relação ao meio ambiente no qual a escola encontra-se inserida; além disso, sugeriram ações para uma maior sustentabilidade no âmbito escolar. A escolha da realização da conferência veio da ideia da Conferência Nacional Infanto-Juvenil pelo Meio Ambiente.

Deboni e Mello (2007, p. 37) expressam a importância de uma conferência sobre meio ambiente na escola:

[...] uma conferência [...] inclui momentos de debate, troca de ideias e reflexões [...] de priorização e tomada de decisões. [...] exige que todos passem a olhar para os problemas socioambientais mais urgentes e definam o que é possível fazer em cada escola e comunidade.

A apresentação dos problemas ambientais identificados na Mata do Queixada, por exemplo, alertou a comunidade escolar sobre o que estava acontecendo. E, a partir da discussão sobre a temática da conferência, os alunos e os professores passaram a pensar em possíveis alternativas e medidas que pudessem ser tomadas no espaço da própria escola. Essas ações se consolidaram por meio dos projetos desenvolvidos para a feira de ciências e pelos projetos ambientais elaborados e aplicados pelos docentes.

$\mathrm{Na}$ feira de ciências, os professores relataram a importância na orientação, estímulo e desenvolvimento de projetos de pesquisa, com temas relevantes para o futuro e para o despertar a consciência dos alunos. Também perceberam que os alunos revelam facilidade e interesse em participar de atividades práticas programadas. Por exemplo, na atividade sobre a poluição da área verde da Mata do Queixada, os alunos questionaram sobre o fato de os próprios moradores jogarem o lixo na mata. Os entrevistados alegaram que isso acontece pela falta de consciência da necessidade de preservação da mata, e pelo fato de não haver coleta de lixo no bairro. E, sem opção, a maioria dos moradores joga o lixo na beira da mata. A partir dessa constatação, os alunos explicaram que no Bairro Colmeia Park existe um ecoponto, para onde pode ser levado o lixo. Foi então que o entrevistado explicou que falta informação na comunidade sobre essas ações.

Observou-se, assim, que houve coerência entre o tema sustentabilidade e o contexto

\footnotetext{
${ }^{7}$ Realizadas durante o processo de avaliação das propostas pedagógicas de EA.
} 
escolar, com uma abordagem proveitosa e uma boa interação entre professores, alunos e comunidade local. Dessa forma, a ação proposta pela feira de ciências representou uma boa estratégia para os alunos iniciarem na pesquisa e, familiarizarem com a escrita de trabalhos científicos.

A elaboração dos projetos ambientais exigiu compartilhamento de saberes, abertura para a discussão de temas relevantes para o contexto escolar, reflexão sobre a prática docente quanto à elaboração e aplicação de projetos como estratégia de ensino da educação ambiental, além do registro e organização de informações que nortearam o trabalho docente. A cada encontro, os planos de trabalho dos grupos de professores eram apresentados e reconstruídos em interação com os demais. Segura (2007) explica que, entre outros elementos essenciais para o desenvolvimento de projetos educativos na escola, o registro é importante porque sistematiza o caminho metodológico adotado, os objetivos, o contexto no qual foi elaborado e concretizado, a avaliação, os atores envolvidos, a análise do que deu certo ou não, ou seja, os aspectos essenciais para sedimentar à ação em EA.

Dentre as dificuldades encontradas pelos professores para a inserção da educação ambiental na escola, no período de desenvolvimento da pesquisa, destaque para: falta de tempo; necessidade de um planejamento mais específico sobre o que trabalhar; trabalhar o tema em sua área de atuação; poucos momentos pedagógicos; acúmulo de conteúdo curricular; preocupação em preparar os alunos para avaliações externas e o déficit na formação docente para a pesquisa. Quanto à questão da falta de tempo, ficou evidente no depoimento de uma professora: "Tenho muitas dificuldades para realizar as atividades de minha disciplina, o tempo não é suficiente para ministrar os conteúdos da matriz de conteúdos, e por isso, não encontro tempo para tratar de educação ambiental no decorrer das aulas" (ENTREVISTA PEB, 2014) ${ }^{8}$.

Em geral, a carga de trabalho do professor na Educação Básica é extensa. Além das atividades extraclasses, correção de avaliações e planejamento das atividades, ainda divide o tempo em casa com os afazeres do lar e a atenção à família. Praticamente, não sobra tempo para a pesquisa, registro da prática docente ou para a formação continuada. Os professores dificilmente são dispensados para realizarem cursos no horário de trabalho. Geralmente devem participar de cursos no período noturno, o que lhes dificulta a participação. Observase, assim, de forma geral, que a inserção da EA na escola revela-se um processo moroso, porém, não deve ser esquecido. É preciso assumir uma postura contínua e diversificada; transformar a insatisfação com a situação atual em motivação para uma participação mais ativa e política diante dos problemas ambientais que envolvem a comunidade local.

\subsection{Reflexões sobre as contribuições do processo de construção e avaliação das práticas pedagógicas em EA no espaço escolar}

Em relação às práticas pedagógicas desenvolvidas, a conferência apresentou-se como uma metodologia estimulante para a reflexão sobre a realidade ambiental local, confirmado pela fala de um professor sobre o evento: "foi o envolvimento da escola no evento e a apresentação do projeto das alunas envolvendo a área do Queixada" (ENTREVISTA PEB, $2013)^{9}$. Essa fala demonstra que os resultados refletem o trabalho em equipe, o compromisso e o empenho nas atribuições de cada docente definida no grupo de discussão. A satisfação dos professores em iniciar o trabalho de orientação dos projetos para a feira de ciências e em elaborar seus próprios projetos ficou explícita durante a pesquisa. O professor $K(2014)^{10}$

\footnotetext{
${ }^{8}$ Realizada durante o processo de avaliação das propostas pedagógicas de EA.

${ }^{9}$ Realizada durante a Conferência sobre o Meio Ambiente.

${ }^{10}$ A identificação $K$ foi usada no texto para garantir o anonimato do professor de Educação Física, que concedeu uma entrevista durante o processo de avaliação dos Projetos Ambientais.
} 
disse: "Pela primeira vez eu estou orientando e estou feliz. O ano passado eu não orientei".

A participação no planejamento e retomada das decisões sobre a intervenção envolveu os docentes nos processos da pesquisa e da ação. A análise do processo de orientação dos projetos também permitiu observar a dificuldade do professor com a pesquisa e com a escrita de projetos. Dos seis professores entrevistados, apenas dois disseram não ter problemas para elaborar um projeto. A professora $I$ (2014) ${ }^{11}$ afirmou: "Não, para mim foi algo novo. Encontrei dificuldade em colocar as ideias no projeto: justificativa, objetivo (...)".

A professora $D$ (2014) ${ }^{12}$ declarou: "Tenho dificuldade também, tenho que estar acompanhando, vendo o do colega". Além disso, relataram outros obstáculos no processo, tais como: dificuldade dos alunos com a pesquisa, a escrita, desinteresse pela leitura de textos científicos, dentre outros. Entretanto, é necessário insistir com a metodologia de projeto de trabalho, haja vista a relevância tanto para a melhoria da escrita e introdução a pesquisa, quanto pelo valor potencial para a EA.

Apesar do sucesso das propostas pedagógicas da conferência ambiental, da feira de ciências e dos projetos ambientais elaborados pelos docentes, ficou evidente que é mais fácil usar o livro didático do que ousar. Esse dado demonstra a necessidade da formação continuada, e a distância existente entre a pesquisa e a prática docente. Duvoisin (2002) explica que incorporar os princípios da pesquisa pode ser um meio para romper com a aquisição mecânica dos conteúdos, propiciando uma relação dialógica, o aumento da autonomia do educando e rompimento com o autoritarismo.

Cabe, também, à equipe gestora propor, em encontros pedagógicos ou coletivos, condições de formação e de elaboração de um PPP que aborde atividades educativas ou projetos integrados, articulando as diferentes disciplinas nos quais haja reflexão crítica da prática. Os dados mostram o potencial das propostas aplicadas e como é possível despertar professores e alunos com um olhar diferenciado para a forma de ensinar e aprender.

A pesquisa propiciou espaços de descobertas, de troca de experiências, de valorização individual e coletiva. E, o mais importante, o envolvimento da comunidade escolar em questões ambientais. Além disso, permitiu a inserção dos temas ambientais no PPP da escola. Para os docentes, o planejamento de propostas articuladas entre as disciplinas permitiu a construção de novas intervenções adequadas à realidade de cada escola. Com essa experiência puderam refletir quanto à natureza interdisciplinar da educação ambiental, como uma responsabilidade de todos. É necessário, portanto, um novo arranjo dos Sistemas de Ensino, na busca de um caminho para a superação da fragmentação do conhecimento característico da especialização das áreas de ensino.

Diversas mudanças são imprescindíveis, por exemplo, a garantia de debates e planejamento de ações específicas para cada problema diagnosticado nas unidades escolares. Por fim, as informações coletadas demonstraram a real necessidade de formação inicial e continuada do professor para o trabalho interdisciplinar em educação ambiental, além disso, desenvolvimento de uma prática docente que una pesquisa e ação. Cabe mais investimento na educação, no sentido de preparar a comunidade educativa para exercer a práxis, aliando, sempre que possível, pesquisa e ação em uma relação dialógica, partindo da problematização da realidade.

\footnotetext{
${ }^{11}$ A identificação $I$ foi usada no texto para garantir o anonimato da professora de Inglês, que concedeu uma entrevista durante o processo de avaliação dos Projetos Ambientais.

12 A identificação $D$ foi usada no texto para garantir o anonimato da professora de Língua Portuguesa, que concedeu uma entrevista durante o processo de avaliação dos Projetos Ambientais.
} 


\section{Considerações finais}

O estudo desenvolvido em uma escola municipal da cidade de Jataí-GO revelou que a educação ambiental é pouco trabalhada de forma articulada ao programa de conteúdo das disciplinas. Há carência de conhecimento docente sobre os temas ambientais e, além disso, falta formação interdisciplinar para os professores. Assim, a inserção dessa área do conhecimento por meio de projetos interdisciplinares na educação formal é uma perspectiva positiva, constando de condições reais de abordagem dos temas ambientais.

Percebeu-se que há elementos complicadores para o desenvolvimento de tais atividades, desde o dispêndio de tempo com as obrigações extraclasse, de elaboração, de correção de atividades inerentes à profissão até a carga excessiva de trabalho e/ou apoio da gestão. Ressalta-se que a falta de formação específica para o trabalho com educação ambiental, especialmente por meio de projetos, potencializa as dificuldades enfrentadas à imersão da educação ambiental no contexto escolar. Todos esses aspectos demonstram a insustentabilidade das condições do trabalho docente e real necessidade de mudanças, iniciando por uma nova configuração para o currículo, a qual deve vislumbrar a formação humana a partir da totalidade. Outra urgência está relacionada à valorização da docência na educação básica, com plano de carreira justo, comparável em igualdade a outros níveis de ensino, garantindo ao profissional direito a dedicação exclusiva. Momentos como o da realização das práticas planejadas pelo grupo de professores na escola abre o debate a uma participação mais ativa da comunidade escolar para discutirem a proposição de ações educativas que possam ser concretizadas.

As propostas pedagógicas aplicadas na escola (conferência ambiental, feira de ciências e projetos ambientais) consistiram em instrumentos participativos na escola. Representaram uma forma de tomada de consciência oportuna à mudança de atitude. Além disso, possibilitaram uma maior interação do grupo para organizar e embasar futuras ações com propostas pedagógicas que atendam às necessidades específicas de cada realidade. A feira de ciências, por exemplo, revelou-se uma experiência diferenciada para a maioria dos docentes.

A abordagem do tema sustentabilidade desencadeou a investigação de problemas ambientais identificados pelos alunos a partir da sua realidade; permitiu um maior conhecimento sobre o espaço de convivência, os hábitos e as atitudes desenvolvidas localmente. As dificuldades apontadas ao longo do estudo não podem atravancar as conquistas que os alunos e docentes revelaram: a ciência deve estar acessível ao aluno e ser entendida na escola como algo sempre em construção, ao seu alcance, podendo ser investigada por ele e analisada com criticidade.

A inserção da educação ambiental na educação formal por meio de investigação, o desenvolvimento de projetos ambientais articulados entre diferentes disciplinas, desencadeou uma expressiva interação na comunidade escolar, nas etapas de planejamento e de execução de ações coletivas pautadas no diálogo. Esse tipo de prática pedagógica se distancia de um ensino tradicional e possibilita um maior envolvimento dos atores no espaço educativo.

Nesse sentido, importa uma escola que forme leitores críticos da realidade e que estabeleça uma relação de significado entre conteúdo/conceitos/pesquisa/ação. Na escola em estudo, os efeitos das metodologias utilizadas para abordagem da educação ambiental imprimiram uma mudança na percepção dos professores em relação à discussão dos temas ambientais. Contribuiu, assim, para um novo trilhar rumo à interdisciplinaridade dentro das condições reais da escola de educação básica. 


\section{Referências}

ALVES, A. Interdisciplinaridade e matemática. In: FAZENDA, I. C. A. (Org.). O que é interdisciplinaridade? 2 ed. São Paulo: Cortez, 2013.

BARDIN, L. Análise de conteúdo. Tradução de Luís Antero Reto; Augusto Pinheiro. São Paulo: Edições 70, 2011.

BIZZO, N. Ciências: fácil ou difícil? São Paulo: Biruta, 2009.

CARVALHO, F; SCOPEL, I. Reflexões sobre a expansão urbana em Jataí-GO e a necessidade de criação do parque ecológico das nascentes da mata do Córrego do Queixada. In: ENCONTRO NACIONAL DOS GEÓGRAFOS, 16, 2010, Porto Alegre. Anais... Porto Alegre: Associação dos Geógrafos $\quad$ Brasileiros, $2010 . \quad$ Disponível em: <http://www.agb.org.br/evento/download.php?idTrabalho=486>. Acesso em: 20 mar. 2013.

DEBONI, F.; MELLO, S. S. Pensando sobre a "geração do futuro" no presente: jovem educa jovem, COM-VIDAS e conferência. In: MELLO, S. S.; TRAJBER, R. (Coord.) Vamos cuidar do Brasil: conceitos e práticas em educação ambiental na escola. Brasília: Ministério da Educação, Coordenação Geral de Educação Ambiental: Ministério do Meio Ambiente, Departamento de Educação Ambiental: UNESCO, 2007.

DIONNE, H. A pesquisa-ação para o desenvolvimento local. Tradução de Michel Thiollent. Brasília: Liber Livro Editora, 2007. (Série Pesquisa, v.16).

DUVOISIN, I. A. A necessidade de uma visão sistêmica para a educação ambiental: conflitos entre o velho e o novo paradigma. In: RUSCHEINSKY, A. (Org.) Educação ambiental: abordagens múltiplas. Porto Alegre: Artmed, 2002. p. 91-103.

FAZENDA, I. C. A. Reflexões metodológicas sobre a tese: "interdisciplinaridade - um projeto em parceria". In: (Org.). Metodologia da pesquisa educacional. 12 ed. São Paulo: Cortez, 2010, p.161-179.

FLICK, U. Introdução à pesquisa qualitativa. Tradução de Joice Elias Costa. 3 ed. Porto Alegre: Artmed, 2009.

FRANCO, M. A. S. Pedagogia da Pesquisa-ação. Educação e Pesquisa, São Paulo, v. 31, n. 3, p. 483502, set./dez. 2005.

GIL, A. C. Como elaborar projetos de pesquisa. 4 ed. São Paulo: Atlas, 2007.

GUIMARÃES, M. A formação de educadores ambientais. 8 ed. Campinas: Papirus, 2012.

JACOBI, P. R. Educação Ambiental: o desafio da construção de um pensamento crítico, complexo e reflexivo. Educação e Pesquisa, São Paulo, v. 31, n. 2, p.233-250, mai./ago. 2005.

JOSÉ, M. A. M. Interdisciplinaridade: as disciplinas e a interdisciplinaridade brasileira. In: FAZENDA, I. C. A. (Org.). O que é interdisciplinaridade? 2 ed. São Paulo: Cortez, 2008. p.85-95.

LEFF, E. Aventuras da epistemologia ambiental: da articulação das ciências ao diálogo de saberes. Tradução de Silvana Cobucci Leite. São Paulo: Cortez, 2012.

LENOIR, Y. Didática e interdisciplinaridade: uma complementaridade necessária e incontornável. In: FAZENDA, I. C. A. (Org.). Didática e interdisciplinaridade. 15 ed. Campinas: Papirus, 1998. p. 4575. (Coleção Práxis). 
LOUREIRO, C. F. B. Emancipação e complexidade: para o repensar das tendências em Educação Ambiental. Cadernos de Educação, Pelotas, v. 1, p. 147-162, 2007.

MOURA, D. G.; BARBOSA, E. F. Trabalhando com projetos: planejamento e gestão de projetos educacionais. 2 ed. Petrópolis: Vozes, 2007.

MORALES, A. G. A formação do profissional educador ambiental: reflexões, possibilidades e constatações. Ponta Grossa: Ed. UEPG, 2009.

SATO, M.; PASSOS, L. A. Biorregionalismo: identidade histórica e caminhos para a cidadania. In: LOUREIRO, C. F. B; LAYARGUES, P.; CASTRO, R. S. (Orgs.) Educação ambiental: repensando o espaço da cidadania. 5 ed. São Paulo: Cortez, 2011. p. 227-259.

SEGURA, D. S. B. Educação ambiental nos projetos transversais. In: MELLO, S. S.; TRAJBER, R. (Coord.) Vamos cuidar do Brasil: conceitos e práticas em educação ambiental na escola. Brasília: Ministério da Educação, Coordenação Geral de Educação Ambiental: Ministério do Meio Ambiente, Departamento de Educação Ambiental: UNESCO, 2007.

SEVERINO, A. J. O conhecimento pedagógico e a interdisciplinaridade: o saber como intencionalização da prática. In: FAZENDA, I. C. A. (Org.). Didática e interdisciplinaridade. 15 ed. Campinas: Papirus, 1998. p. 31-44. (Coleção Práxis).

SEVERINO, A. J Metodologia do trabalho científico. 23 ed. São Paulo: Cortez, 2007.

TOZONI-REIS, M. F. C. Educação ambiental: natureza, razão e história. Campinas: Autores Associados, 2004.

TRINDADE, D. F. Interdisciplinaridade: um novo olhar sobre as ciências. In: FAZENDA, I. C. A. (Org.). O que é interdisciplinaridade? 2 ed. São Paulo: Cortez, 2008. p.65-83. 